Salyut-7

\section{Cosmonaut crisis exaggerated}

REPORTS in the US journal Aviation Week that the Soviet orbital spacecraft Salyut-7 suffered a rupture in a main oxidizer line at the beginning of September have triggered speculation that this could put at risk the lives of cosmonauts Vladimir Lyakhov and Aleksandr Aleksandrov. These suggestions (which did not have the backing of the Aviation Week "analysts") have been formally denied by Soviet space planners. The launch last week of the cargo ship Progress-18 was announced in terms which made it clear that no early return to Earth was contemplated. This replenishment craft carried fuel supplies for Salyut-7, rations for the crew, and also materials for further experiments, Tass said last week.

But the Tass statement has not ended speculation in Western newspapers. There are said to be two main dangers threatening the cosmonauts. First, if the Salyut is still losing fuel, it might become impossible to make essential orbital corrections. There is also the problem of the cosmonauts' return to Earth. Transport to and from the Salyut stations is by the Soyuz two or three-person transport craft. For longer flights, these craft have the major disadvantage that after about 115 days in orbit, the propellant tanks, batteries and some of the sensitive electronics are considered to be too unreliable to ensure a safe return to Earth. If the cosmonauts are to remain in space longer than three months, they will need a new spacecraft for their return trip.

This, in normal conditions, presents no great problem. The Salyut has a docking unit at each end, so that it is perfectly feasible for a second Soyuz to dock with the complex while the original transport craft is still in place. This replacement is normally effected by sending up a short-term guest-crew before the safe life of the original Soyuz has expired; the guests then return to Earth aboard the old Soyuz, leaving the new one coupled to the Salyut.

Unfortunately, the replacement Soyuz that should have been launched at the end of September blew up on the launch pad (its

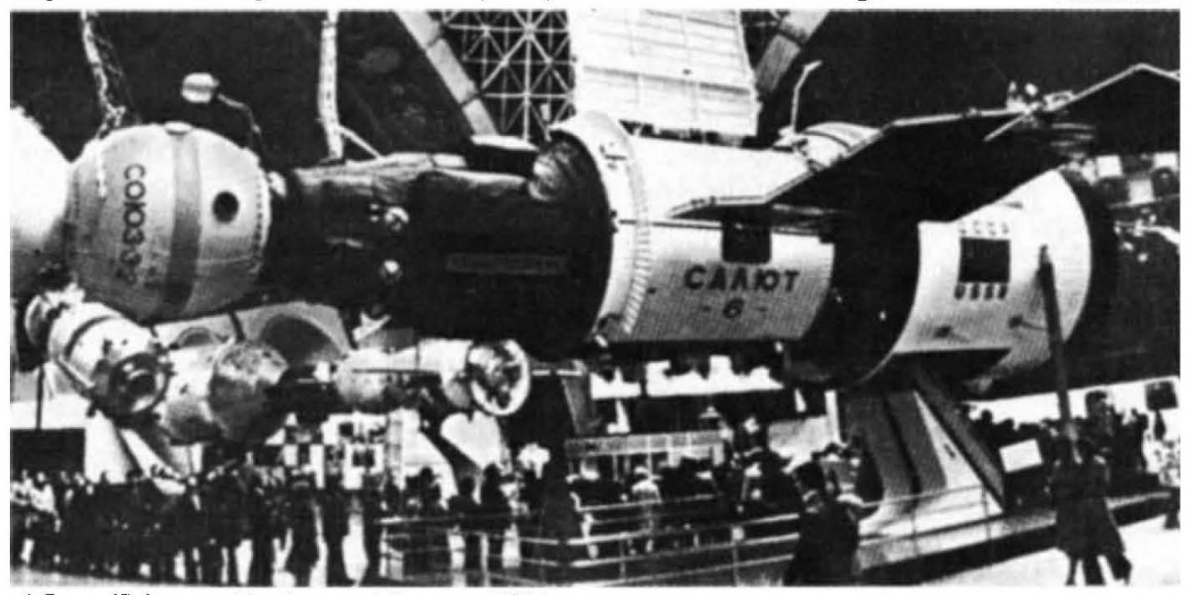

A Soyuz/Salyut combination at a Moscow exhibition

crew of three only narrowly escaping with their lives). Since Soyuz-T-9, which carried Lyakhov and Aleksandrov up to Salyut-7, is now almost four months old, they will need a new craft in which to return.

This should, in itself, pose no difficulties. Following other problems in the past, notably the docking failures of Soyuz-25 and 33, the Soviet manned programme has previously been temporarily suspended. After the recent even more serious incident, the space planners may well wish to make a thorough investigation of what caused the explosion before attempting another manned flight. If, however, it becomes imperative to bring Lyakhov and Aleksandrov back to Earth, it would still be possible to send up an unmanned Soyuz to dock automatically with Salyut.

The idea put forward in some newspapers that the Soviets may have sent up Progress-28 to keep the cosmonauts alive until they can be rescued by the US shuttle in November is somewhat fanciful - such a rescue would, theoretically, be possible but replenishment by Progress is a routine feature of long-term stays on Salyut and should not be interpreted as a symptom of alarm.

Indeed, the only definite signs of concern for the safety of the cosmonauts have come not from the engineers but from Soviet physicians. Cosmonauts on previous long-term missions have shown a significant decline in activity and efficiency during their fourth month in space. This time it is hoped to counter this by a major change in the experimental programme. During the first three months, the cosmonauts concentrated on geophysical observations, but from now on they are to work on the production of new semiconductor crystals and biologically pure substances. Furthermore, to improve their physiological well-being and to overcome the sense of isolation from Earth reported by their predecessors, Lyakhov and Aleksandrov are woken each morning by recorded bird-song.

Vera Rich

0028-0836/83/430756-01\$01.(0)
Spanish universities

\section{Autonomy on trial \\ Barcelona}

AFTER a marathon two-day debate, the Law for University Reform was approved by the Spanish Senate before the summer recess and is now taking effect. The Socialist majority in both houses wanted quick approval and the bill passed through Parliament without any major change; the Senate did not alter a single word. A previous bill, the so-called Law for Autonomy of the University, remained in Parliament under four successive ministers of education, and suffered many changes before being withdrawn by the last centrist government a year ago.

The new Law for University Reform is intended to provide a general framework for higher education in Spain. It defines the university as a public service, and higher education as the right of everyone who wishes to pursue it. The law is intended to help Spanish universities to achieve their objectives of "scientific development, the education of professionals and the spreading of culture".

Under the new law, university institutions will have much greater autonomy in both economic and academic matters. The universities will now have the right to change their curricula, to select their own professors, to decide their own internal statutes and to administer money from the state and from their own resources. All these changes are intended to encourage diversity and competition among Spanish universities. Most of these measures have long been sought by university authorities.

One part of the law that has surprised many scholars has been that relating to professors. Contrary to previous socialist party policy, the law does not change the traditional status of of professors as civil servants. Only a limited number of visiting and associate professors with fixed-term contracts will be allowed. Professors will be divided into "titular" professors and "catedrático", both tenured but with no specifically different functions. To become a full professor (catedrático), three years experience as a titular professor will be necessary. The system of selection of teaching staff has also been modified, with a procedure based on candidates' curricula vitae instead of the classical examination procedure (oposiciones). All the teaching staff now under contract will in the next four years have an opportunity to achieve a permanent position through a special procedure. Spanish scientists working abroad can also take part under certain conditions.

There has been a rush to introduce the changes in time for the academic year now beginning. Not until the system has been running for at least a year will the real effects of the law on Spanish universities be known.

Pedro Puigdoménech 